\title{
AS CONTRIBUIÇõeS DE VIGOTSKI PARA O CENÁRIO EDUCACIONAL BRASILEIRO: AS FUNÇÕES PSICOLÓGICAS SUPERIORES EM FOCO
}

\begin{tabular}{c}
\hline THE VYGOTSKY'S CONTRIBUTIONS FOR EDUCATIONAL SCENARIO BRAZIL: \\
THE HIGHER MENTAL FUNCTIONS IN FOCUS \\
\hline LAS CONTRIBUCIONES DE VIGOTSKI PARA EL ESCENARIO EDUCACIONAL \\
BRASILEÑO: LAS FUNCIONES PSICOLÓGICAS SUPERIORES EN FOCO
\end{tabular}

\section{RESUMO}

Antonio Dário Lopes Júnior ${ }^{\mathrm{i}}$

Betânea Moreira de Moraes ${ }^{\text {ii }}$

O presente estudo é fruto de nossa pesquisa de mestrado, durante o qual objetivamos sinalizar algumas das contribuições de Vigotski para o cenário educacional brasileiro. Trata-se de um estudo de natureza teórica, realizado mediante pesquisa bibliográfica, sendo dividido em dois momentos principais. No primeiro, apresentamos um levantamento do processo de difusão do pensamento do referido autor no cenário educacional mundial, com ênfase em sua chegada ao Brasil. No segundo, trazemos as tensões entre a importância conferida aos aspectos biológicos e sociais para o processo de desenvolvimento do gênero humano, tendo em vista que o autor reconhecia a existência das funções psicológicas elementares e superiores, a primeira radicada em nossa origem biológica e a segunda fixada dentro das relações entre indivíduo e sociedade. Tal reflexão servirá de base para sinalizar, à luz da teoria de Vigotski, a importância do professor e da escola no processo de humanização do homem.

PALAVRAS-CHAVE: Vigotski. Educação. Funções psicológicas superiores.

\begin{abstract}
This Study is the result of our research for the master thesis, wherein we aim to point some of the Vygotsky's contributions for the Brazilian educational landscape. That is a theoretical study, achieved by bibliographical research and divided into two main moments. In the first one, we present an inventory of the process of this author's thought dissemination on the educational world stage, with emphasis on its arrival in Brazil. In the second one, we bring the tensions between the importance attached to the biological and social aspects for the development process of humankind, considering that the author acknowledged the existence of the lower and higher mental functions. The first one rooted in our biological origins and the second one established into the relations between individuals and society. In view of Vygotsky's theory this consideration will serve as a basis to set how important the teacher and the school are in the process of humanization.
\end{abstract}

KEYWORDS: Vygotsky. Education. Higher mental functions.

\section{RESUMEN}

Este estudio es fruto de nuestra investigación del máster, mientras el cual aspiramos a indicar algunas de las contribuciones de Vigotsky para el escenario educacional brasileño. Se trata de un estudio de naturaleza teórica, realizado mediante investigación bibliográfica, que está dividido en dos momentos principales. En el primero, presentamos una recogida y un tratamiento del proceso de difusión del pensamiento del citado autor en el escenario educacional mundial, con énfasis en su llegada al Brasil. En el segundo, traemos las tensiones entre la importancia conferida a los aspectos biológicos y sociales para el proceso de desarrollo del género humano, teniendo en cuenta que el autor reconocía la existencia de las funciones psicológicas elementares y superiores, las primeras radicadas en nuestro origen biológico y las segundas fijas dentro de las relaciones entre individuo y

\begin{tabular}{l|c|c|c|c|c|c|} 
(C) Rev. Educ. Perspec. & Viçosa, $M G$ & v.8 & n.1 & p.72-88 & jan./abr. 2017 & eISSN 2178-8359 \\
\hline
\end{tabular}


sociedad. Tal reflexión servirá de base para probar, a la luz de la teoría de Vigotsky, la importancia del maestro y de la escuela en el proceso de humanización del hombre.

PALABRAS CLAVE: Vygotski. Educacíon. Funciones psicológicas Superiores.

\section{INTRODUÇÃO}

Muitos carecimentos que a vida social nos proporciona e que nos diferencia dos animais é a possibilidade de transformar tais carecimentos em perguntas e buscarmos respostas. Nesse sentido, a pergunta que ora fazemos refere-se a compreender de que maneira Vigotski adentra no cenário educacional brasileiro, além de buscar esclarecer o papel do professor na formação das funções psíquicas superiores.

Este esforço não é novo e encontra ressonância nas assertivas desenvolvidas por Duarte (2007), Facci (2004), Mainardes e Pino (2000) e Lima, Carmo e Jimenez (2010). No entanto, consideramos necessário fazer um contraponto à naturalização do pensamento de Vigotski nos dias atuais, tendo em vista o modo como este se hegemoniza no ideário educacional, principalmente por meio de obras que buscam facilitar a compreensão de seu pensamento, deixando, por vezes, aspectos importantes de sua obra relegados a segundo plano.

Dito isto, a primeira parte de nosso estudo se constitui de uma sistematização preliminar, na qual discorreremos sobre a difusão do pensamento de Vigotski no ocidente, sua popularização e concomitante assepsia. Tal higienização refere-se particularmente aos fundamentos marxianos na psicologia de Vigotski, bem como as dificuldades daí advindas.

A defesa de uma leitura marxiana de Vigotski se torna necessária para se ter possibilidade de compreender os lineamentos teóricos do psicólogo soviético e esta é a tônica da segunda parte deste artigo, na qual abordaremos a gênese e o desenvolvimento das funções psicológicas superiores. Salientamos que nos estudos da Escola de Vigotski encontramos as funções psicológicas elementares e superiores. As primeiras são radicadas em nossa origem enquanto seres biológicos e se configuram em nossas capacidades básicas inatas. Já as funções psicológicas superiores, nos sãos outorgadas por meio de nossas relações sociais, sendo necessário o contato com outros seres humanos para que possamos adquiri-las no processo de hominização do homem. Para se compreender como se dá este processo, a ontologia marxiano-lukacsiana é de extrema relevância, especialmente no que se refere às categorias: trabalho, história, mediação e instrumentos. Nesse sentido, destacamos que as funções psicológicas superiores não são naturais, mas sociais, reconhecendo a importância da mediação na sua formação, assim como do instrumento neste processo, o qual atua como o médium da atividade humana. 


\section{A APROPRIAÇÃO dOS ESTUDOS DE VIGOTSKI NO CENÁRIO EDUCACIONAL BRASILEIRO}

Em linhas gerais, o processo de difusão dos estudos vigotskianos no ocidente ocorre em dois momentos distintos: o primeiro, anterior aos acontecimentos da Segunda Guerra Mundial e o segundo nos desdobramentos da Guerra Fria. Consoante ao apresentado por Burgess (1995), vale destacarmos que na década de 1930 buscavam-se nos estudos de Vigotski subsídios para o entendimento acerca do significado da palavra, da fala interna e da contribuição da linguagem para o intelecto. Já na década de 1970, as obras do autor soviético eram perscrutadas em busca de substratos para o auxílio da sociolinguística para a valorização da variabilidade linguística e do bilinguismo, além dos dialetos e padrões, os quais serviram de base para os estudos culturais.

Tal segmentação permitiu certa polarização das leituras de Vigotski dentro do cenário educacional inglês, o qual pode ser considerado um preâmbulo, uma espécie de porta de entrada para seus estudos no ocidente, de maneira geral. No primeiro grupo de temáticas, o autor passa a ser filiado aos estudiosos que abordam questões pertinentes ao papel do símbolo na atividade humana, buscando-se em Vigotski conceituações acerca da aprendizagem, do desenvolvimento e do papel da linguagem no pensamento; tendendo aos estudos do símbolo e da simbolização. Tal preocupação científica era justificada pelo fato de que esse aspecto teórico, adaptava-se bem "à ênfase na criatividade e na contribuição ativa da criança em sua própria aprendizagem.” (BURGUESS, 1995, p. 35). Acreditamos que esse grupo, embora não negligenciasse o aspecto social, tomava-o em termos mais genéricos, dando maior ênfase a categorias como interação, distanciada da sociabilidade, desconsiderando o homem como sujeito social e historicamente mediado. Tal fato devia-se à grande influência que o pensamento neokantiano teve nos estudos que surgiram no período pós-guerra, dentre os quais podemos destacar as elaborações de Piaget (BURGUESS, 1995).

O segundo grupo, por outro lado, buscavam-se em Vigotski os fundamentos para discutir a questão da política e da cultura, tendo como principal influência a política cultural de Antonio Gramsci e, em decorrência das propostas do autor italiano, pretendiam superar o suposto idealismo alemão denunciado por Marx. Assim, para Burguess (1995, p. 37), "nessa leitura, o pensamento de Vygotsky está relacionado à luta cultural e política.”.

Embora ocorra uma apropriação distinta da letra de Vigotski nestes momentos, um elemento era comum: o sentimento de medo com relação ao que acontecia dentro da União Soviética (URSS). Tal fato era justificado pela "hostilidade em relação à stalinização da psicologia soviética como também da intolerância para com o pensamento marxista." (BURGESS, 1995, 
p. 44). Nesses termos, os estudos que eram desenvolvidos na URSS acabavam sendo considerados, por muitos países ocidentais, como uma espécie de subversão ideológica.

Nesse contexto, os pesquisadores ocidentais que porventura estivessem interessados nos estudos do autor soviético tiveram que defendê-lo em um terreno movediço e bastante hostil com relação à sua base teórica. Assim, se arvoraram de um subterfúgio bastante problemático para facilitar a defesa de suas ideias no ocidente: a adaptação ou supressão das chamadas repetições desnecessárias ou das partes consideradas menos importantes dos artigos de Vigotski. Acerca desse processo, ao retomar os estudos apresentados por Sève, autores como Duarte (2004) e Tuleski (2008) denunciam que tal expediente incidiu, particularmente, nas reflexões marxistas presentes em seus estudos, "como se elas fossem extrínsecas à sua teoria psicológica e, portanto, suprimíveis sem prejuízo para a compreensão do pensamento do autor." (DUARTE, 1996, p. 19).

Sinalizar este dado histórico torna-se importante, pois vai ao encontro do teor das versões da obra de Vigotski que chegam ao Brasil, seguindo um movimento das questões sociais de sua época, mas com as limitações impostas por esse momento. Com efeito, a partir da segunda metade dos anos de 1970 e nos anos de 1980, o contexto histórico e político, principalmente a efervescência do processo de redemocratização do país, ofereceu condições favoráveis à retomada das discussões educacionais numa perspectiva crítica. Registra-se que em universidades como a Universidade Estadual de Campinas (Unicamp) e a Pontifícia Universidade Católica de São Paulo (PUC-SP), aos poucos foram se formando grupos de estudiosos da obra de Vigotski, os quais influenciaram a formação de outros grupos em São Paulo, Minas Gerais e Rio de Janeiro (MAINARDES; PINO, 2000). No entanto, a via de acesso aos estudos do autor se dava por meio das versões provenientes dos EUA, bem como Inglaterra, as quais sofreram com o mecanismo de censura.

Nos anos de 1980, ocorreu também a retomada das discussões acerca dos currículos, os quais passavam por reformas substanciais, tendo por objetivo resgatar a "a relevância social dos conteúdos veiculados na escola, contrapondo-se às orientações tecnicistas que prevaleceram na década anterior." (BARETTO, 2000, p. 8-9). O foco recaía na recuperação da importância do saber veiculado pela escola, visto como um instrumento de exercício da cidadania plena e como elemento capaz de contribuir para a transformação das relações sociais vigentes (BARETTO, 2000).

Lembremos que uma das vias de difusão dos estudos de Vigotski buscava a legitimação da luta cultural e política. Em meio a esse movimento, sinalizamos a importância das versões brasileiras das obras "Mind in Society", de 1984, e "Tought and Language", de 1987 (MAINARDES; PINO, 2000). Muito embora tais obras se configurem como referências

\begin{tabular}{l|c|c|c|c|c|c} 
(C) Rev. Educ. Perspec. & Viçosa, $M G$ & v.8 & n.1 & p.72-88 & jan./abr. 2017 & eISSN 2178-8359 \\
\hline
\end{tabular}


básicas para a assimilação de Vigotski no cenário brasileiro, denunciamos que as mesmas constituem uma colcha de retalhos da teoria, na qual os editores inseriram de modo equivocado, materiais provindos das mais diversas obras, seja do próprio autor, seja de algum colaborador; no intuito de consubstanciar uma maior clareza às elaborações de Vigotski. Com efeito, segundo os editores, as obras do psicólogo soviético eram difíceis de serem apreendidas, ora devido a problemas de tradução, ora porque o autor era identificado como prolixo (FACCI, 2004; DUARTE, 2004; CARMO, 2008), como afirmam Mainardes e Pino (2000, p. 256):

As poucas obras de Vigotski disponíveis em português, todas elas traduções de textos americanos soltos, alguns deles incompletos, somado ao fato de serem essas obras de leitura aparentemente fácil e de o leitor freqüentemente não atentar à fundamentação marxista que marca o pensamento de Vigotski, explicam a diversidade de leituras que revelam os trabalhos ditos de orientação vigotskiana.

A problemática que a difusão dessas obras gera para a apreensão do pensamento de Vigotski no ideário educacional reside no fato de que o autor soviético passa a ser famoso e referenciado entre os educadores brasileiros, antes mesmo de ser verdadeiramente conhecido por eles. É oportuno ressaltar que o contato com o pensamento do autor se deu por obras que se propunham a "aprimorar" ou facilitar a escrita vigotskiana (DUARTE, 2007). O engodo fica evidente, em uma análise preliminar das obras, que se configura como um apanhado de ideias parciais e provisórias de quem está estudando o autor.

Como contraponto a essa leitura ora equivocada, ora superficial da teoria vigotskiana, reconhecemos que o autor viveu e militou dentro da Rússia Soviética, tendo um enorme apreço pelas proposições de Marx, as quais tomou como suporte para a formulação de uma psicologia verdadeiramente científica. Essa referência ao pensamento de Marx é uma característica constante em muitos de seus intérpretes. No entanto, conforme assinala Duarte (2011, p. 3):

[...] o fato de ser admitida essa influência não implica necessariamente a aceitação da tese de que a característica central da psicologia vigotskiana seja a de constituirse e uma contribuição para a construção de uma psicologia marxista. Ou seja, muitos autores podem admitir que Vigotski tenha sido, de alguma forma, influenciado pelo marxismo e, mesmo assim, apresentarem uma leitura do pensamento desse autor que o afasta do universo político-ideológico de luta pela superação do capitalismo e pela construção de uma sociedade socialista.

Ao asseptizarem a teoria de Vigotski, retirando seus pressupostos marxianos, muitos autores fazem uma apropriação indevida dos fundamentos revolucionários de sua psicologia. Com efeito, ancorados nas propostas de Duarte (1996, p. 22), afiançamos que, muito embora não seja necessário ser marxista para se ler o pensamento de Vigotski, acreditamos ser muito pouco provável que as proposições dele possam ser apropriadas "sem um mínimo de

\begin{tabular}{l|l|l|l|l|l|l} 
(c) Rev. Educ. Perspec. & Viçosa, $M G$ & v.8 & n.1 & p.72-88 & jan./abr. 2017 & eISSN 2178-8359 \\
\hline
\end{tabular}


conhecimento da filosofia de Marx, de seu método, de sua concepção do homem como um ser histórico."

Prosseguiremos pondo em destaque a concepção histórica sobre o desenvolvimento das funções psicológicas, evidenciando a sua estreita relação com os postulados marxianos, principalmente no que se refere ao papel do instrumento no desenvolvimento do homem, em particular, na passagem das funções psíquicas elementares para funções psíquicas superiores.

\section{O TORNAR-SE HOMEM DO HOMEM: AS FUnÇõeS PSICOLÓGICAS SUPERIORES}

As funções psicológicas superiores (FPS) podem ser consideradas um dos assuntos mais importantes abordados por Vigotski, principalmente ao nos reportarmos a suas contribuições para a esfera educacional, tendo em vista que estas não são inerentes ao ser humano (em seu aspecto biológico), mas são desenvolvidas por meio da mediação, do contato com a cultura, se convertendo praticamente em uma segunda natureza. No entanto, para que possamos nos aproximar desta temática, tentaremos examiná-la brevemente, em sua relação com as particularidades da atividade consciente do homem, tendo em vista que estas são interdependentes; como se a atividade consciente fosse o palco no qual as funções psicológicas superiores atuam.

Neste sentido, nosso primeiro passo consiste em explicitar de que forma a perspectiva inaugurada pela Escola de Vigotski se contrapõe às propostas até então vigentes, as quais, segundo Rivière (2002), eram vinculados por uma perspectiva a-histórica, materializada em uma tendência em reduzir a problemática das FPS, quer a uma dimensão espiritual, quer natural.

Reconhecemos que a primeira forma de se encarar a questão nasce da filosofia idealista, partindo de uma visão dualista de mundo. Luria (1991) afirma que a tese básica dessa corrente atribuía as acentuadas diferenças entre o comportamento humano e do animal a um princípio espiritual que existia no homem em detrimento dos demais animais.

A segunda, por outro lado, filia-se ao positivismo evolucionista, que identificava as particularidades da atividade consciente do homem como fruto direto de sua evolução do mundo animal, uma vez que já se podia "observar nos animais todos os fundamentos da consciência humana" (LURIA, 1991, p. 74). No entanto, as tentativas de se encontrar nos rudimentos biológicos os fundamentos do ser social constituíram uma tarefa inócua.

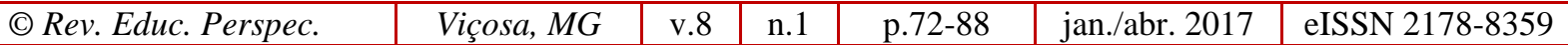


A problemática inerente ao desenvolvimento histórico foi relegada a segundo plano e em decorrência desse processo passou a se confundir "o natural e o cultural, o natural e o histórico, o biológico e o social no desenvolvimento psíquico da criança. Dito brevemente, ambas as perspectivas, têm uma compreensão radicalmente errônea da natureza dos fenômenos que estuda." (VYGOTSKI, 2012, p. 12, tradução livre).

Com efeito, tais fundamentos denotavam perspectivas psicológicas associais, as quais, muito embora pudessem tratar acerca da história, se negavam a reconhecê-la enquanto força motriz para o desenvolvimento do espírito. Assim, em contrapartida, temos a perspectiva inaugurada por Vigotski e seguida por Luria e Leontiev que introduz uma nova maneira de investigar o problema. Para os autores, devemos rejeitar as proposições metafísicas, as quais isolam a atividade consciente do homem da vida real. "Devemos, pelo contrário, estudar como a consciência do homem depende do seu modo de vida humano, da sua existência." (LEONTIEV, 2004, p. 98). Uma vez que as particularidades dessa atividade são gestadas na tessitura das relações historicamente produzidas pelo conjunto dos homens, acabam por modificar a estrutura da própria atividade. Tendo como desdobramento direto desse pressuposto, toda função psicológica superior é social (JIMENEZ; CARMO, 2007). Em suma, as raízes da atividade consciente do homem não deveriam ser procuradas nas peculiaridades da alma, nem no íntimo dos organismos, mas nas condições sociais de vida historicamente formadas.

Para Vigotski (2009), uma forma de desenvolvimento não pode ser encarada como a simples continuação direta de outro, muito pelo contrário, ocorre uma mudança no próprio tipo de desenvolvimento, da conduta regida por princípios biológicos, para a lei histórico-social. Como assinalam Leontiev (2004) e Facci (2004), mesmo que o homem, visto em seu caráter filogenético já possa ser considerado como um homem, é apenas por meio da interação com o outro, com o mundo que o cerca, o mundo feito de objetos e de fenômenos gestados pelas gerações anteriores, que se objetiva o desenvolvimento do complexo psiquismo humano.

No entanto, afirmar a legalidade das leis sócio-históricas, no que se refere às singularidades do ser social, não nos faz desconsiderar a importância dos aspectos biológicos, tendo em vista que para Lukács existem três esferas ontológicas distintas, a inorgânica, a orgânica e o ser social: o ser inorgânico, o mineral, não possui vida, sua evolução consiste em apenas se tornar outro; o ser biológico, por outro lado, tem a característica da reprodução, ele cria um novo ser, mas este novo é sempre o mesmo; por fim, a terceira esfera, configura o surgimento do ser social, o qual tem como particularidade a contínua produção do novo, de maneira conscientemente orientada (GONÇALVES; JIMENEZ, 2013). 
Por meio das contribuições de Lukács (2013), apoiado em Marx, reconhecemos que o trabalho e o advento das leis históricas promovem um progressivo afastamento das barreiras naturais. No entanto, embora possa haver uma distinção ontológica entre as três esferas do ser, elas estão ineliminavelmente articuladas, consistindo em momentos preparatórios que podem ter ocorrido em um hiato de milhões ou bilhões de anos, nos quais se madurou a passagem de uma forma a outra de ser. Retomando o pensamento de Lukács, Gonçalves e Jimenez (2013) asseveram que a relação entre as três esferas traduz a processualidade humana.

Dessa forma, conseguimos apreender que a gênese da forma tipicamente humana não pode ser vista como uma produção inerente à esfera orgânica do ser. Com efeito, como assinalam Gonçalves e Jimenez (2013), isto só se torna possível a partir da presença de um órgão que atue como um médium próprio desse estatuto de ser, o qual pode ser caracterizado como a consciência. A conduta humana difere sobremaneira da dos demais seres vivos, tendo em vista que, por sua estreita relação com a esfera biológica, estes possuem apenas duas fontes para o seu desenvolvimento: “1) os programas hereditários de comportamento jacentes no genótipo e 2) os resultados da experiência individual.” (LURIA, 1991, p. 73). No ser humano, por outro lado, encontramos uma terceira fonte, uma vez que "a grande maioria dos conhecimentos e habilidades do homem se forma por meio da assimilação da experiência de toda a humanidade, acumulada no processo da história social e transmissível no processo de aprendizagem.” (LURIA, 1991, p. 73, grifo do autor).

Apoiados nos estudos da Escola de Vigotski, conseguimos apreender que, em meio à sua relação com a natureza, o animal deve se adaptar a esta por meio de mudanças em sua própria morfologia, órgãos ou na estrutura de seu corpo. No humano, por outro lado, a forma de adaptação ao meio se modifica por completo, daí podemos destacar o nascimento de órgãos artificiais e os instrumentos (VYGOTSKI, 2012).

Assim, os instrumentos podem ser caracterizados como objetos sociais e mesmo que algumas vezes sejam frutos de uma prática individual, nascem permeados tanto pela relação do homem com a natureza, quanto pela relação dos homens com os demais membros da sociabilidade. Nesse sentido, conforme assinala Leontiev (2004, p. 90), mesmo "o conhecimento humano mais simples, que se realiza diretamente numa ação concreta de trabalho com a ajuda de um instrumento, não se limita à experiência pessoal de um indivíduo, antes se realiza na base da aquisição por ele da experiência e da prática social.” Portanto, o processo de confecção de instrumentos carece de justificativa em termos estritamente biológicos; só adquirindo sentido em decorrência de seu uso posterior (LUKÁCS, 2013), ou em uma relação com a totalidade social.

(C) Rev. Educ. Perspec.

Viçosa, $M G$

V.8

\begin{tabular}{l|l} 
n.1 & p.72-88
\end{tabular}

jan./abr. 2017

eISSN 2178-8359 
Com efeito, para Marx (2014), a ferramenta se configura como uma coisa, ou complexo de coisas que o trabalhador insere entre si mesmo e o objeto de trabalho, o qual lhe serve para dirigir sua atividade a este objeto. Faz-se de algo existente na natureza um órgão de sua própria atividade, "um órgão que acrescenta a seus próprios órgãos corporais, aumentando seu corpo natural" (p. 213), os quais, mesmo que não guardem nenhuma relação direta com a situação existente, são postos a serviço da adaptação ativa do ser social. Para Vygotski (2012), trata-se de uma característica fundamental das formas superiores de conduta.

Salientamos o papel do instrumento neste processo como médium da atividade humana. É oportuno destacar, a partir de Vygotski (2012), que a relação de similaridade entre os instrumentos e os signos se baseia em sua função mediadora, sendo diferenciadas no objeto no qual exerce essa mediação; enquanto a utilização das ferramentas auxilia o homem no domínio da natureza, os signos o auxiliam no domínio da própria conduta.

Em outros termos, por meio do emprego funcional dos signos, o homem saiu dos limites impostos a ele enquanto um ser biológico, havendo uma complexificação na esfera de suas atividades ou, conforme Vygotski (2012, p. 95):

\begin{abstract}
A aplicação dos meios auxiliares, e a maneira como a atividade mediadora reconstrói a raiz de toda a operação psíquica, semelhante de como a aplicação das ferramentas altera a atividade natural dos órgãos e amplia infinitamente o sistema de atividade das funções psíquicas. Tanto um como para o outro, podemos chamá-lo em seu conjunto, com o termo de função psíquica superior ou conduta superior. (Tradução livre, grifo do autor).
\end{abstract}

Evidencia-se, assim, que as funções psicológicas superiores não são dadas pelo aparato biológico, mas aparecem primeiro em suas relações sociais para depois serem internalizadas. Desse modo, auxiliam na reconstrução da atividade interna, a qual a posteriori, servirá como forma de intervir na atividade externa. Junto com Facci (2004), afiançamos que, a formação dos processos psicológicos superiores ocorre, em nível ontogenético, quando os seres humanos se apropriam, na coletividade, da cultura já produzida, num processo não de simples adaptação, mas de transformação da natureza a partir do trabalho, por meio do qual se supera a determinação biológica ao se criar novas necessidades que conduzirão a novas objetivações. Assim, com o auxílio dos signos, como ferramenta, o homem passa a controlar voluntariamente sua atividade psicológica, ampliando consideravelmente suas capacidades de memorização, percepção, atenção, dentre outras funções psicológicas, as quais só são possíveis mediante a apropriação dos bens culturais produzidos ao longo da história da humanidade. 


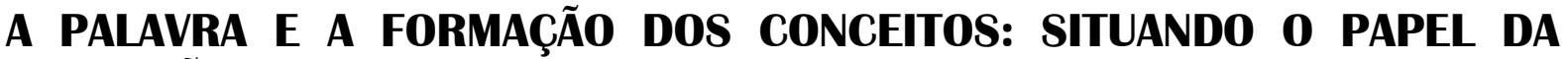 EDUCAÇÃO}

Ao longo deste artigo, discorremos sobre o papel desempenhado pela herança biológica e as determinações sociais para a formação das funções psicológicas superiores como particularidades que constituem a humanidade no homem. Assim, conforme Marx (2010), o animal produz apenas aquilo de que necessita imediatamente, para si ou sua cria, apenas sob a insígnia da necessidade, uma produção unilateral. Já o homem produz mesmo na ausência da carência, se apropriando da natureza sensível e (re)produzindo de forma universal, se defrontando de forma livre com os produtos de sua atividade.

Com efeito, o homem ao nascer não adentra em um mundo regido exclusivamente pelas leis naturais, mas em um mundo moldado pela atividade humana. De certa maneira, sobe nos ombros da geração anterior, se apropriando dos materiais, capitais e forças de produção e ordem social, as quais podem ser posteriormente alteradas de acordo com as necessidades (MARX; ENGELS, 2007) socialmente impostas. Vale ressaltar que o primeiro requisito para que o ser pertencente ao gênero humano se humanize se configura na apropriação da riqueza, tanto material, quando espiritual, socialmente produzida, a qual se dá por meio da educação.

A educação é o processo pelo qual desenvolvemos os meios que nos auxiliarão no processo de apropriação do conhecimento historicamente acumulado. Percebê-lo enquanto categorias e fenômenos, e em termos práticos, como um complexo presente no ser social, além da forma como será viabilizada e desenvolvida, irá variar conforme os interesses sociais e o processo da divisão em classes.

Compreendemos que a linguagem consiste em um importante vetor para esse desenvolvimento. Com efeito, Lukács (2013, p. 223) exorta que a linguagem pode ser considerada como o órgão responsável pela reprodução e continuidade do ser social:

Ela também já o é quando funciona apenas como linguagem falada e exerce o papel
de portadora da continuidade através da tradição oral. Porém, de sua essência
resulta que - nisto ela é uma autêntica manifestação do ser social - essa sua fixação
das conquistas é aperfeiçoada mediante a fixação de si mesma na linguagem escrita.

Tal continuidade se deve ao fato de que, por meio dela, se consegue os rudimentos para a apropriação dos instrumentos e signos socialmente desenvolvidos, os quais, no princípio, atuam como meios de influência sobre o comportamento de outro, para que, em um momento posterior, possam atuar em um meio de influência sobre o próprio comportamento (VYGOTSKI, 2012). Em outras palavras, a característica comum a todas as funções

(C) Rev. Educ. Perspec.

\begin{tabular}{l|l} 
Viçosa, $M G$ & v.8
\end{tabular}

n.1 1

jan./abr. 2017

eISSN 2178-8359 
psicológicas superiores, reside no fato de serem processos mediados e, como tal, incorporam à sua estrutura, "como parte central de todo o processo, o emprego de signos como meio fundamental de orientação e domínio nos processos psíquicos.” (VIGOTSKI, 2009, p. 161).

Desta forma, Vygotski (2012) defende que a natureza humana vem a ser o conjunto de suas relações sociais internalizadas e convertidas em funções da personalidade, e em formas de sua estrutura. Vale ressaltar que, quando tratamos sobre as relações sociais não nos limitamos às relações com o seu grupo social direto, mas no modo com o qual o ser humano se relaciona com todas as conquistas do gênero.

Nesses termos, exortamos o papel primordial da escola no processo de reprodução do ser social, uma vez que se constitui no lócus privilegiado para a apropriação dos instrumentos de trabalho. Na medida em que o ser humano é um ser social, o meio de apropriação desses instrumentos não é engendrado apenas pela experiência imediata, mas também, através da palavra ou dos conceitos. Lukács (2013) assinala que a linguagem, mesmo a mais cotidiana, transmite a universalidade do objeto. Tal pensamento vai ao encontro das proposições da Escola de Vigotski, tendo em vista que, para ele, o processo de formação de conceitos exige o emprego de signos e palavras. Por meio da palavra o ser humano consegue ultrapassar os limites da percepção imediata do mundo exterior, discriminando os elementos mais importantes da realidade; relacionando categorias que pela percepção imediata poderiam ser considerados diferentes, ou diferenciar aqueles que, apesar de sua semelhança externa pertencem a campos díspares da realidade (LURIA, 1986; 1994).

Para Saviani (2011), a educação consiste no ato de produzir, direta e intencionalmente, em cada indivíduo singular, a humanidade que é produzida histórica e coletivamente pelo conjunto dos homens. Nesse sentido, o real destaque da prática educativa se configura em sua intencionalidade. $\mathrm{O}$ professor, por meio da sistematização do conhecimento socialmente acumulado, o transmite ao seu aluno, favorecendo o seu processo de apropriação dessa riqueza.

Para a real efetivação de sua práxis, ao professor é necessário a identificação dos elementos culturais que precisam ser apropriados pelo indivíduo, o que pode ser visto como a chave de acesso para a sua humanização, na medida em que os capacita a reagir adequadamente aos acontecimentos e às situações novas e imprevisíveis que lhe acompanharão ao longo da vida enquanto ser social (LUKÁCS, 2013; SAVIANI, 2011).

Assim, retomamos a diferenciação que Vigotski estabelece entre desenvolvimento e aprendizagem, a qual ocorre por meio de um processo educativo, tendo em vista que o primeiro é orientado enquanto uma força interna ao indivíduo, radicado em seu aparato

\begin{tabular}{l|c|c|c|c|c|c} 
(C) Rev. Educ. Perspec. & Viçosa, $M G$ & v.8 & n.1 & p.72-88 & jan./abr. 2017 & eISSN 2178-8359 \\
\hline
\end{tabular}


biológico, enquanto o segundo nos é proporcionado por forças estranhas ao sujeito, "já que na natureza não existe uma criança cujas funções aritméticas amadureçam espontaneamente" (VYGOTSKI, 2012, p. 154). Com este exemplo, o psicólogo soviético nos apresenta, as peculiaridades do processo de formação de conceitos, os quais, a exemplo das funções aritméticas, não se desenvolvem por meio de uma maturação biológica, mas sim, por meio da mediação, da intervenção de outro que tanto pode estar em seu entorno, ou no espaço escolar.

Nesse sentido, o psicólogo soviético destaca a formação dos conceitos em duas categorias distintas, quais sejam: os conceitos cotidianos e conceitos científicos. Os primeiros são aqueles que nascem da relação do sujeito com o seu entorno imediato, no qual as generalizações se dão por meio da experiência prática. Tais generalizações proporcionam ao indivíduo uma compreensão sincrética da realidade, caracterizada por Vigotski (2009) como uma pluralidade não ordenada, carecendo de uma discriminação.

Já os conceitos científicos, por outro lado, estão para além destes; inserindo o indivíduo e o objeto em um complexo sistema de determinações lógico-verbais, os quais conferem aos alunos ferramentas para articular, aperfeiçoar e corrigir as impressões do cotidiano, quando necessário, as quais são possíveis mediante a prática pedagógica.

A respeito da relação entre os conceitos cotidianos e científicos, Vigotski (2009, p. 244) assinala que:

\footnotetext{
O curso do desenvolvimento do conceito científico nas ciências sociais transcorre sob as condições do processo educacional, que constitui uma forma original de colaboração sistemática entre o pedagogo e a criança, colaboração essa em cujo processo ocorre o amadurecimento das funções psicológicas superiores da criança com o auxílio e a participação do adulto. No campo do nosso interesse, isto se manifesta sempre na crescente relatividade do pensamento causal e no amadurecimento de um determinado nível de arbitrariedade do pensamento científico, nível esse criado pelas condições de ensino.
}

Reconhecemos que uma das principais diferenças entre esses dois conceitos consiste na forma de sistematização e apreensão da realidade. Tal diferenciação, embora pareça pequena, se reverte de grande importância, uma vez que a primeira está baseada na empiria e nas relações que a criança trava diretamente com o mundo à sua volta sem uma intencionalidade. A segunda, uma atividade guiada e sistemática, na qual a criança pode vivenciar situações que exijam dela capacidades que estão para além de sua maturação biológica, ou daquilo que é promovido pelo seu meio direto. Assim, compreendemos, conforme as elaborações de Facci (2004, 2006), que a escola ocupa um lugar privilegiado para a apropriação do conhecimento científico, cabendo ao professor organizar as atividades pedagógicas de forma a dirigir o desenvolvimento psicológico dos alunos.

\begin{tabular}{l|c|c|c|c|c|c} 
(C) Rev. Educ. Perspec. & Viçosa, $M G$ & v.8 & n.1 & p.72-88 & jan./abr. 2017 & eISSN 2178-8359 \\
\hline
\end{tabular}


A autora ao retomar os estudos da Escola de Vigotski e da pedagogia histórico-crítica advoga que, o desenvolvimento das funções psicológicas superiores é dependente da convivência dos seres humanos com seus pares, uma vez que, por meio deste contato ocorre a a superação do biológico pela utilização de mediadores produzidos para suprimir as necessidades postas historicamente. Assim, o professor nesse processo passa a ter uma contribuição fundamental no desenvolvimento das FPS, uma vez que, o ensino é tido como o sistema de organização dos meios pelos quais se transmite ao indivíduo a experiência elaborada pela humanidade (FACCI, 2004). Para Vigotski o bom ensino é aquele que se adianta ao desenvolvimento. Neste contexto o conteúdo trabalhado pelo professor, no processo educativo, cria, individualmente, novas estruturas mentais (ou neoformações) evolutivas decorrentes dos avanços qualitativos no desenvolvimento da criança.

Dito de outro modo, o professor, por meio da prática pedagógica, converte o saber objetivo em saber escolar, de forma que torne a experiência socialmente acumulada pela sociedade assimilável para o aluno, sendo por meio deste processo de apropriação do mundo externo, por meio do processo de internalização, que o aluno está apto a desenvolver as funções psicológicas superiores (FACCI, 2004).

Dessa forma, acreditamos que ao examinarmos o desenvolvimento do caráter social das funções psicológicas superiores e a educação escolar, estamos abordando o aspecto da mediação exercida por um de seus principais agentes, que é o professor. Em contraponto às perspectivas que o secundarizem em detrimento de uma educação pautada no cotidiano, asseveramos ser possível defender uma educação que fomente a autonomia intelectual e moral, a qual problematize a realidade alienada da sociedade; justamente através da transmissão das formas mais elevadas e desenvolvidas do conhecimento socialmente existente.

\section{CONCLUSÃO}

A breve exposição que desenvolvemos e que agora se finaliza, teve por objetivo principal demonstrar a importância dos estudos de Vigotski para o desenvolvimento das funções psicológicas superiores na educação escolar, bem como sinalizar para a importância da prática docente nesse processo.

Nesse sentido, reafirmarmos a problemática envolvendo a forma como se deu a entrada da obra de Vigotski no ocidente, na qual grande parte de sua fundamentação filosófica foi suprimida especialmente por meio de uma inclinação do ocidente em aderir às determinações teóricas norte-americanas.

(C) Rev. Educ. Perspec.

Viçosa, $M G$

v.8

n.1 1 p.72-88

jan./abr. 2017

eISSN 2178-8359 
No segundo momento, ao retomarmos os postulados do autor, ancorados nos postulados marxianos, buscamos destacar o brilhantismo da letra Vigotskiana, foi suprimida pelos censores. Demonstramos que um de seus principais postulados advoga sobre a diferenciação existente entre a atividade animal e humana. Onde aquela é demarcada sob a lógica do sistema de maturação biológica, enquanto a atividade humana é engendrada por meio da apropriação da cultura e da riqueza socialmente desenvolvida por meio do trabalho. Assim o autor demonstra a diferenciação clara entre desenvolvimento e aprendizagem e as suas repercussões para a educação, lançamos às sementes para se repensar os aspectos inerentes a própria formação docente.

Ao tratar sobre o signo e a palavra, assinalamos como estes auxiliam o homem no domínio da natureza e de sua própria conduta, exortando a importância da mediação neste processo. Desta forma, pavimentamos o caminho para se pensar na formação de conceitos, os quais nascem da relação entre pensamento e palavra, se configurando como lentes para significar as diversas facetas da realidade sensível.

Desta forma, a apropriação dos conceitos tanto pode se dar a partir do cotidiano, da internalização da realidade sensível, ou por meio da sistematização do conhecimento socialmente desenvolvido - os conceitos científicos, a partir dos quais se pensa a realidade para além do aparente organizando o sensível por meio de relações lógico-verbais, o qual só é possível por meio da prática docente.

No entanto, embora esta seja a função docente, asseveramos que em uma sociedade edificada a partir da exploração de uma classe sobre a outra, o que se espera da escola e da prática docente se refere a uma exaltação do aspecto cotidiano em detrimento do saber científico e a secundarização do papel do professor, o que implica negativamente na elevação das funções psíquicas superiores e na apreensão do conhecimento historicamente acumulado pela humanidade.

\section{REFERÊNCIAS}

BARRETTO, Elba Siqueira de Sá. Tendências recentes do currículo do Ensino Fundamental no Brasil. In: BARRETTO, Elba Siqueira de Sá (Org.). Os currículos do ensino fundamental para as escolas brasileiras, São Paulo, Autores Associados, 2000.

BURGESS, Tony. Ler Vygotsky. In. DANIELS, Harry. (Org.) Vygotsky em foco: pressupostos e desdobramentos, 2.ed. Campinas, SP, Paripus, 1995. 
CARMO, Francisca. Maurilene. Vigotski: um estudo à luz da centralidade ontológica do trabalho. 2008. 201 f. Tese (Doutorado em Educação Brasileira) - Faculdade de Educação (FACED). Universidade Federal do Ceará, Fortaleza - Ceará, 2008.

CARMO, Francisca Maurilene; JIMENEZ, Susana Vasconcelos. Psicologia históricocultural: indicações para uma leitura marxista de Vigotski. Contrapontos, UNIVALI, v. 7, p. 283-297, 2007.

CARMO, Francisca Maurilene; JIMENEZ, Susana Vasconcelos. Em busca das bases ontológicas da psicologia de Vygotsky. Psicol. estud., Maringá, v. 8, n. 4, Dec. 2013. Disponível em: <http://www.scielo.br/scielo.php?script=sci_arttext\&pid=S1413$73722013000400005 \& \operatorname{lng}=$ en\&nrm=iso>. Acesso em: 03 mar. 2015.

DUARTE, Newton. A Escola de Vigotski e A Educação Escolar. Revista Psicologia USP, São Paulo: USP, v. 7, n. 1/2, p. 17-50, 1996. Disponível em: <http://www.revistas.usp.br/psicousp/article/view/34531/37269>. Acesso em: 12 jan. 2015.

DUARTE, Newton. Educação escolar, teoria do cotidiano e a escola de Vigotski. $4^{\text {a }}$ ed. Campinas-SP, Autores Associados, 2007.

DUARTE, Newton. Vigotski e o "aprender a aprender": crítica às apropriações neoliberais e pós-modernas da teoria vigotskiana. 3.ed. Campinas-SP, Autores Associados, 2004.

FACCI, Marilda Gonçalves Dias. Valorização ou esvaziamento do trabalho do professor?: um estudo crítico-comparativo. Campinas: SP, Autores Associados, 2004.

GONCALVES, Ruth Maria de Paula; JIMENEZ, Susana Vasconcelos. Relações antagônicas entre sentido e significado do trabalho no capital: uma análise na perspectiva ontológica.

Psicol. Soc., Belo Horizonte, v. 25, n. 3, p. 685-694, 2013 . Disponível em:

<http://www.scielo.br/scielo.php?script=sci_arttext\&pid=S0102-

$71822013000300022 \& \operatorname{lng}=$ pt\&nrm=iso $>$. Acesso em: 18 ago. 2015.

LEONTIEV, Alexis. O desenvolvimento do psiquismo. São Paulo, Centauro, 2004.

LIMA, Marteana Ferreira.; CARMO, Francisca Maurilene; JIMENEZ, Susana Vasconcelos. Por uma leitura onto-marxista de Vigotski e seus desdobramentos na relação trabalhoeducação. In: JIMENEZ, Susana, RABELO, Jackline, MENDES SEGUNDO, Maria das Dores (Orgs.); Marxismo, educação e luta de classes: pressupostos ontológicos e desdobramentos ideo-políticos, Fortaleza, EdUECE, 2010.

LUKÁCS, George. Para uma ontologia do ser social. São Paulo, Boitempo, 2013. v. 2

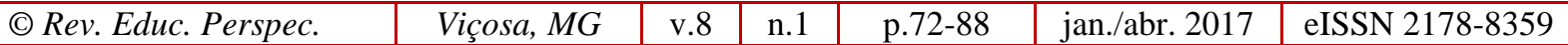


LURIA, Alexander Romanovich. Curso de Psicologia Geral. Rio de Janeiro, Civilização Brasileia, 1991. v. 1

LURIA, Alexander Romanovich. Curso de Psicologia Geral. Rio de Janeiro, Civilização Brasileia, 1994. v. 4

LURIA, Alexander Romanovich. Pensamento e Linguagem: as últimas conferências, Porto Alegre, Artes Médicas, 1986.

MAINARDES, Jefferson; PINO, Angel. Publicações brasileiras na perspectiva vigotskiana. Educ. Soc., Campinas, v. 21, n. 71, jul. 2000. Disponível em: <http://www.scielo.br/ scielo.php?script=sci_arttext\&pid=S0101-73302000000200012\&lng=en\&nrm=iso $>$. Acesso em: 16 mar. 2015.

MARX, Karl; ENGELS, Friedrich. A ideologia alemã. São Paulo, Boitempo, 2007

MARX, Karl. Manuscritos econômico-filosóficos. São Paulo, Boitempo, 2010.

MARX, Karl. O Capital: crítica da economia política, livro 1. Rio de Janeiro, Civilização Brasileira, 2014.

RIVIÈRE, Angel. La psicología de Vygotski, Madrid, A. Machado libros, 2002.

SAVIANI, Demerval. Pedagogia histórico-crítica: primeiras aproximações, Campinas, SP, Autores Associados, 2011.

TULESKI, Silvana Calvo. Vygotski: A construção de uma psicologia marxista, 2.ed. Maringá, Eduem, 2008.

VIGOTSKI, Liev Semionovich. A construção do pensamento e da linguagem. 2.ed. São Paulo, Martins Fontes, 2009.

VYGOTSKI, Liev Semionovich. Obras Escogídas: Problemas del desarrollo de la psique, Tomo III, Madrid, Visor, 2012.

\section{Agradecimentos}

Agradecemos ao CNPq pela bolsa de mestrado concedida e ao Programa de Pós-Graduação em Educação da Universidade Estadual do Ceará (PPGE- UECE). 


\footnotetext{
${ }^{\text {i }}$ Antonio Dário Lopes Júnior - Professor da Faculdade Joaquim Nabuco. Graduado em psicologia pela Universidade Estadual do Ceará e Mestre em Educação pela Universidade Estadual do Ceará. E-mail: adlopesjunior@hotmail.com

ii Betânea Moreira de Moraes - Professora da Universidade Estadual do Ceará, Centro de Educação, Curso de Pedagogia. Formada em Psicologia, com doutorado em Educação e pós-Doutorado em Psicologia Social. E-mail: betaneamoreas@ hotmail.com

ii Ruth Maria de Paula Gonçalves - Professora da Universidade Estadual do Ceará, Centro de Humanidades, Curso de Psicologia. Formada em Pedagogia, com doutorado em Educação e pós-Doutorado em Psicologia Social. E-mail: ruthm@ secrel.com.br
}

Submetido em: 20-10-2016 - Aceito em: 17-04-2017.

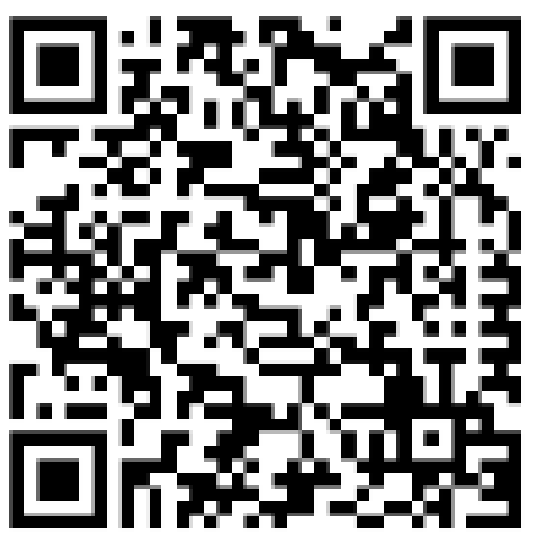

